\title{
Produção da amora-preta cv tupy, em função da intensidade da poda
}

\section{Production of blackberry cv tupy, depending on the intensity of pruning}

\author{
Leonardo Tullio ${ }^{1 *}$; Ricardo Antonio Ayub ${ }^{2}$
}

\section{Resumo}

O cultivo da amora-preta vem crescendo cada vez mais no Brasil, devido as suas qualidades nutricionais. Seu manejo é fundamental para a qualidade do fruto, em especial a poda de produção. O objetivo deste trabalho foi avaliar o efeito da intensidade de poda na produção da amora-preta cv Tupy na região de Ponta Grossa, PR. O delineamento experimental inteiramente aleatorizado consistiu em seis tratamentos com três repetições, sendo os tratamentos: $\mathrm{T}_{1}-2$ hastes; $\mathrm{T}_{2}-3$ hastes; $\mathrm{T}_{3}-4$ hastes; $\mathrm{T}_{4}-5$ hastes; $\mathrm{T}_{5}-6$ hastes e $\mathrm{T}_{6}-8$ hastes, num total de 18 parcelas com 3 plantas cada. Foram avaliados: produção por planta, massa fresca do fruto, sólidos solúveis, coloração e firmeza. O número de hastes deixadas durante a poda afeta a produtividade da amora-preta cv. Tupy, sendo para os parâmetros produção por planta e número de frutos por planta o número de hastes ideal é de 7,8 . O número de hastes por planta não interferiu na massa fresca, sólidos solúveis, firmeza e coloração dos frutos. Considerando facilidade de manejo e produtividade recomenda-se trabalhar com 6 hastes por planta.

Palavras-chave: Rubus spp, condução de plantas, número de ramos

\begin{abstract}
The blackberry crop is growing increasingly in Brazil, due to their nutritional qualities. Its management is essential for fruit quality, especially the production pruning. The objective of this study was to evaluate the effect of pruning intensity in the production of blackberry cv Tupy in the region of Ponta Grossa, PR. The entirely randomized experimental design consisted of six treatments with three repetitions, being the treatments: $\mathrm{T}_{1}-2$ rods, $\mathrm{T}_{2}-3$ rods, $\mathrm{T}_{3}-4$ rods, $\mathrm{T}_{4}-5$ rods, $\mathrm{T}_{5}-6$ rods and $\mathrm{T}_{6}-8$ rods, a total of 18 parcels with 3 plants each. Were evaluated: plant production, fresh fruit, soluble solids, firmness and color. The number of stems left during pruning affects the productivity of blackberry cv. Tupy. For the parameters yield per plant and number of fruits per plant the ideal number of stems is 7,8 . The number of stems per plant did not influence the fresh weight, soluble solids, firmness and color of the fruit. Considering productivity and ease of management is recommended to work with 6 stems per plant.
\end{abstract}

Key words: Rubus spp, plant training, number of branches

\footnotetext{
${ }^{1}$ Eng $^{\circ} \mathrm{Agr}^{\circ}$, Especialista em Agronegócio, Prof. Assistente no Centro de Ensino Superior dos Campos Gerais, CESCAGE, Ponta Grossa, PR. E-mail: nardotullio@hotmail.com

${ }^{2}$ Eng $^{\circ}$ Agr $^{\circ}$, Prof. Dr. Associado, Universidade Estadual de Ponta Grossa,UEPG, Ponta Grossa, PR. E-mail: rayub@uepg.br

* Autor para correspondência
} 
O cultivo das chamadas "pequenas frutas", morango, amora-preta, framboesa, groselha, mirtilo entre outras, vem aumentando no Brasil pela possibilidade de obtenção de alto retorno econômico, embora sejam exigentes em mão de obra.

Os EUA lideram a produção mundial de amorapreta, com 11.905 hectares e produção de 35.099 toneladas (PAGOT et al., 2007) vindo em segundo lugar o Chile com área plantada de 1.111 hectares e produção de 4.275 toneladas (STRIK et al., 2007). Já no Brasil os maiores produtores são o Rio Grande do Sul, Santa Catarina, Paraná e Minas Gerais. Estimase que existem 300 ha plantados com essa fruta no Brasil com uma produção total de 780 toneladas, das quais cerca de 15\% são exportadas para a Europa, sendo plantada principalmente a cultivar Tupy. A maior parte da produção é processada em geleias e sucos e utilizada para consumo no mercado interno (STRIK et al., 2007).

A cultivar Tupy, a mais cultivada no Brasil, é resultado do cruzamento entre as cultivares Uruguai $\mathrm{x}$ Comanche (ANTUNES; REGINA; DUARTE FILHO, 2002), apresenta porte ereto, com espinhos, produz frutos grandes de 8 a $10 \mathrm{~g}$ de massa média, teor de sólidos solúveis entre $8^{\circ}$ e $9^{\circ}$ Brix, com coloração preta e uniforme (EMBRAPA, 2008). É uma planta exigente em frio e, seus aspectos fisiológicos podem variar de ano para ano em função das condições climáticas.

A sua produção ocorre em ramos do ano, enquanto alguns ramos estão frutificando, outras hastes emergem e crescem, renovando o material para a próxima safra (FACHINELLO et al., 1994). A produtividade pode alcançar até 10 ton. ha $^{-1}$ ano $^{-1}$ (ANTUNES; REGINA; DUARTE FILHO, 2002).

No primeiro ano de plantio, as hastes que brotam da coroa das mudas devem ser raleadas, deixando apenas quatro hastes por planta (PAGOT et al., 2007). A poda de inverno é realizada encurtando todos os galhos laterais a $30-40 \mathrm{~cm}$, com o objetivo de organizar o espaço na linha e distribuir melhor a frutificação. Junto com a poda de inverno, realiza-se uma seleção das hastes mais vigorosas, eliminandose o excesso. Segundo, Embrapa (2008), realiza-se dois tipos de poda, a primeira para retirar as hastes que produziram na safra, realizando cortes rente ao solo, e a segunda encurtando os ramos do ano, preparando-os para a próxima safra.

A produção da amora-preta é dependente, em parte, do número de gemas deixado nas hastes após a poda de inverno (TAKEDA, 2002). A redução do número de hastes e a diminuição do comprimento das hastes laterais, geralmente diminui a produção devido ao menor número de gemas florais, mas pode melhorar a qualidade do fruto em amoras e framboesas (CRANDALL; DAUBENY, 1990).

Porém a falta de conhecimento mais específicos quanto a resposta da planta a diversos fatores e a falta de pesquisas sobre amoreira no Brasil pode ser um entrave para a cultura. Com base nisso o presente trabalho teve como objetivo avaliar o efeito da intensidade de poda na produção da amora-preta cv Tupy na região de Ponta Grossa, PR.

O experimento foi realizado no município de Ponta Grossa-PR. O local situa-se a 25¹0'38,69" latitude sul e 50²'21,67' longitude oeste a 879 metros de altitude. O clima segunda a classificação de Köppen é $\mathrm{Cfb}$ - Clima temperado propriamente dito; temperatura média no mês mais frio abaixo de $18^{\circ} \mathrm{C}$ (mesotérmico), com verões frescos, temperatura média no mês mais quente abaixo de $22^{\circ} \mathrm{C}$ e sem estação seca definida, com precipitação anual de $1500 \mathrm{~mm}$. O tipo de solo é classificado segundo o Sistema Brasileiro de Classificação de Solos como Latossolo vermelho distrófico.

A cultivar utilizada foi Tupy, plantada em janeiro de 2009, conduzidas em sistema de espaldeira com um fio de arame, espaçamento de $0,80 \mathrm{~m}$ entre plantas e $2,80 \mathrm{~m}$ entre linhas, perfazendo um total de 4500 plantas por hectare. O experimento foi conduzido no ano de 2010, em plantas formadas e no segundo ano de produção. 
O delineamento experimental inteiramente casualizado consistiu em seis tratamentos com três repetições, sendo os tratamentos: $\mathrm{T}_{1}-2$ hastes; $\mathrm{T}_{2}-3$ hastes; $\mathrm{T}_{3}-4$ hastes; $\mathrm{T}_{4}-5$ hastes; $\mathrm{T}_{5}-6$ hastes e $\mathrm{T}_{6}-8$ hastes, num total de 18 parcelas com 3 plantas cada. A poda foi realizada no dia 03/09/2010, o início do florescimento se deu no dia 04/10/2010.

A colheita dos frutos foi realizada semanalmente ou quando necessário, três vezes por semana, coletando-se apenas os frutos maduros, por meio de análise visual da coloração. Iniciou-se a colheita no dia $15 / 11 / 2010$ e foi até $17 / 01 / 2011$, neste período foi realizada a contagem de frutos e a pesagem, ao final da colheita realizou-se as somas de todos os dados coletados e obteve-se a produção total por planta de cada parcela.

Para a caracterização pós colheita dos frutos, as parcelas foram colhidas separadamente em recipiente plástico sem tampa e levadas até o laboratório para as análises. Foram amostrados 10 frutos por tratamento, os quais foram submetidos a análise de cor, firmeza e sólidos solúveis. A cor do fruto foi determinada com o Colorímetro Minolta CR 400, o qual apresenta os valores de L*, a* e b*. O valor $\mathrm{L}^{*}$ indica a luminosidade do branco ao preto, $\mathrm{a}^{*}$ indica o eixo da cromaticidade do verde (-) ao vermelho $(+)$ e o b* o eixo da cromaticidade do azul (-) ao amarelo (+). A partir destes valores, foi calculado o ângulo hue $\left(\mathrm{h}^{\mathrm{o}}\right)$, expresso em graus, pela fórmula $h^{o}=\tan ^{-1} b^{*} / a^{*}$, que caracteriza $a$ tonalidade dos frutos.

A firmeza do fruto foi medida utilizando um penetrômetro manual, marca McCornick FT 327 com ponteira de $8 \mathrm{~mm}$ de diâmetro, sendo a leitura realizada na seção equatorial dos frutos, e o resultado expresso em Newton $(\mathrm{N})$.

O teor de sólidos solúveis (SS) foi medido por refratometria, realizado com um refratômetro portátil, marca DIGIT modelo 103, sendo o resultado expresso em ${ }^{\circ}$ Brix.
O manejo das plantas daninhas foi realizado com roçada, sendo necessário três vezes. Os ramos secundários ou ladrões foram retirados da planta, quando os mesmos apresentavam-se maiores que as plantas da parcela, afim de evitar alguma influência sobre os resultados do experimento.

As análises estatísticas da Anava foram realizadas utilizando o programa SISVAR e as análises de regressão ao nível de $1 \%$.

Verificou-se que houve aumento na produção da amoreira cultivar Tupy com o aumento do número de hastes por planta (Figura 1). Com 2 hastes a produção foi de $1,297 \mathrm{Kg}$ por planta, que resultaria em uma produção de $5.836 \mathrm{Kg} \cdot \mathrm{ha}^{-1}$, com 6 hastes a produção por planta foi de $2,359 \mathrm{Kg}$ ou 10.615 Kg.ha ${ }^{-1}$. No tratamento com 8 hastes, considerando assim o máximo número de hastes, a produção foi de 2,368 Kg por planta ou $10.656 \mathrm{Kg} \cdot \mathrm{ha}^{-1}$.

Esses valores são superiores aos encontrados por Santos, Raseira e Madail (1997) trabalhando com a cultivar Tupy, em que a produtividade da amoreira em regiões de clima temperado para o primeiro ano é de $5.000 \mathrm{Kg} \cdot \mathrm{ha}^{-1}$, segundo ano $7.500 \mathrm{Kg} \cdot \mathrm{ha}^{-1}$ e terceiro ano $12.000 \mathrm{Kg} \cdot \mathrm{ha}^{-1}$. Quando se observa os valores de produtividade, esses são relevantes, visto que em segundo ano de produção obteve-se valores superiores. Antunes (1999) analisando o comportamento da cultivar Tupy, sustentada em espaldeira dupla, com espaçamento de 0,7 × $3 \mathrm{~m}$, em Poços de Caldas-MG onde apresenta temperatura média de $17^{\circ} \mathrm{C}$ e precipitação média de $1700 \mathrm{~mm}$, observou produtividade de $7.540 \mathrm{Kg} \cdot \mathrm{ha}^{-1}$ e 7.250 Kg.ha-1 ${ }^{-1}$ em primeiro e segundo ano de produção, nas safras de 1997/1998 e 1998/1999 respectivamente. 
Figura 1. Produção total de frutos de amora-preta por planta em resposta a intensidade de poda.

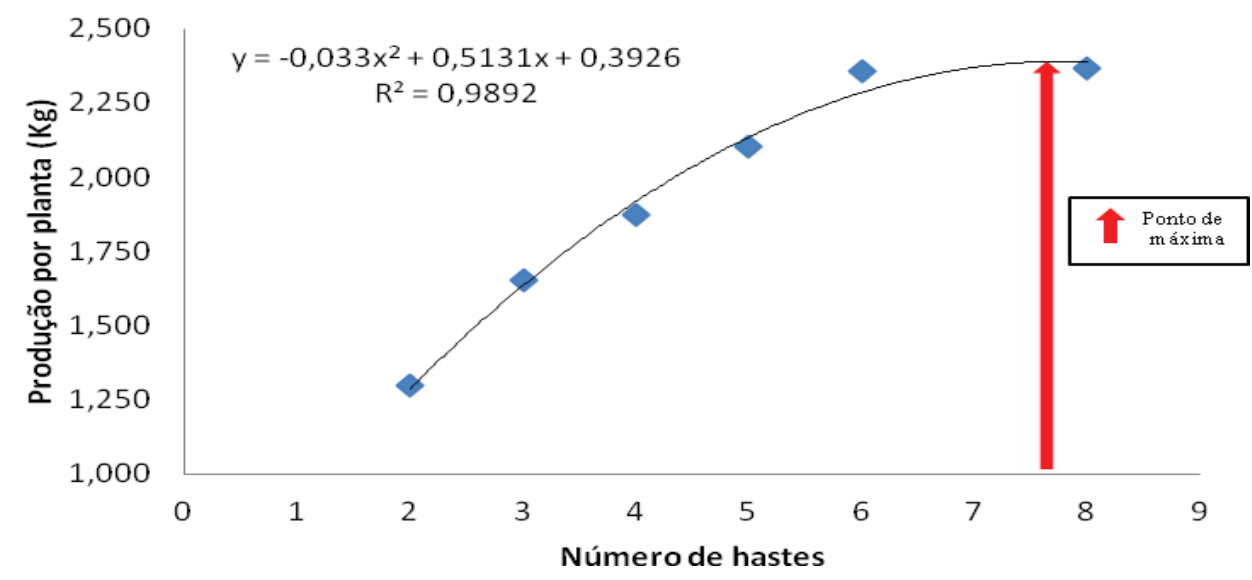

Fonte: Elaboração dos autores.

Figura 2. Número total de frutos de amora-preta por planta em resposta da intensidade de poda.

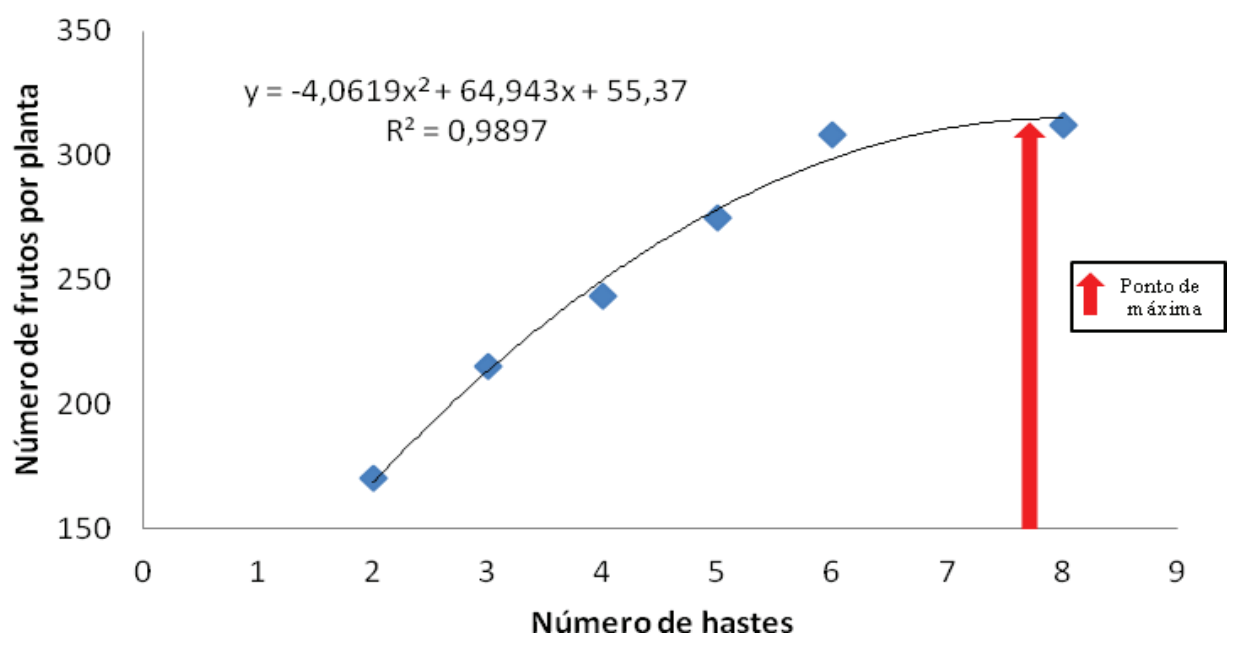

Fonte: Elaboração dos autores.

O ponto de máxima produção por planta, determinado pela equação do gráfico, é alcançada com 7,8 hastes (Figura 1). No entanto, este tratamento não é recomendado em função da dificuldade de manejo das plantas, principalmente pela quantidade de espinhos da cultivar. Pagot et al. (2007) recomendam para a amora 4 hastes, porém os resultados deste experimento mostram que o tratamento com 6 hastes apresentou boa produtividade, associada a satisfatória qualidade de frutos e viabiliza adequado manejo das plantas.
Com relação ao número de frutos, observou-se incremento do número de frutos com o aumento do número de hastes (Figura 2). Broetto et al. (2009), trabalhando com a cultivar Xavante em sistema orgânico e utilizando poda longa e poda curta, encontraram um maior número de frutos em tratamentos com poda longa, o número de gemas florais deixados nos ramos influenciou diretamente no número de frutos produzidos, concordando com os resultados deste experimento. 
O ponto de máximo número de frutos foi obtido com 7,8 hastes por planta (Figura 2). Este número é muito superior ao recomendado por Pagot et al. (2007) para a cultura, indicando que plantas conduzidas com este número de hastes apresentariam problemas de manejo.

$\mathrm{O}$ aumento de produção observado em tratamentos com mais hastes deve-se ao maior número de frutos produzidos e não a incrementos de massa fresca destes frutos. Não houve diferença significativa de massa fresca entre os tratamentos, o que está de acordo com dados obtidos por Takeda (2002), para amora-preta 'Black Satin', conduzida em sistema "V".

O valor médio de massa fresca do fruto, obtido foi de 7,6 gramas, sendo superior aos dados encontrados por Santos e Raseira (1988) que descrevem a cultivar Tupy com frutos grandes, 6,6 g e próximo aos dados apresentados por Antunes (2004) que descreve os frutos da variedade com 8 a $10 \mathrm{~g}$. Isso pode ter ocorrido devido as condições climáticas, em especial ao índice pluviométrico que nesse período foram frequentes, totalizando $20 \mathrm{~mm}$ no mês, pois quanto mais água disponível no solo, mais será absorvida pela planta e conseqüentemente suas células apresentarão maior turgescência, deixando assim o fruto com maior massa fresca.

De acordo com Antunes, Duarte Filho e Sousa (2003), os teores de sólidos solúveis para a cultivar Tupy estão entre 9 e $10{ }^{\circ}$ Brix, também Antunes (2004) cita valores entre $8^{\circ}$ e $9^{\circ}$ Brix, discordando dos $5^{\circ}$ Brix encontrado neste trabalho. Mas está de acordo com os resultados observados por Torres (2007) para os frutos de amora-preta cv. Tupy, que encontrou valores próximos de 5,0 ${ }^{\circ}$ Brix. Já Boer e Ayub (2011) trabalhando com o armazenamento de amora cv Tupy encontraram valor 4,0 $0^{\circ}$ Brix. Estes dados evidenciam a grande variação entre os resultados, o que pode ser justificado por diferença de condições climáticas, variando de ano para ano e de região para região, associadas aos diferentes sistemas de cultivo utilizado para a amora-preta.
Em relação a firmeza de polpa os valores médios foram de $8,2 \mathrm{~N}$, esse valor indica que os frutos estão com boa firmeza, característica importante quando trata-se do transporte da fruta até o consumidor final. Esse valor foi próximo ao encontrado por Boer e Ayub (2011) que variou de 5,5 a 8,0 N para a cv Tupy. Sousa (2007) trabalhando com a cv Arapaho, encontrou valor igual a 3,8 N. A firmeza do fruto da amora-preta cv. Tupy está relacionada diretamente com a evolução de estádio fenológico, ou seja, a medida que ocorre a maturação dos frutos a firmeza vai diminuindo.

A tonalidade, representada pelo ângulo HUE (h), foi de 0,41 , indicando que os frutos estão mais escuros com a coloração próxima ao vermelho. Valor esse superior ao encontrado por Boer e Ayub (2011), que variou de 0,27 a 0,29 para a cv Tupy. Valores de h próximos de $0^{\circ}$, representam coloração próxima ao vermelho puro, proveniente de elevados teores antociânicos presentes no fruto (SILVA et al., 2010).

O valor 13,94 encontrado para a luminosidade, indica que os frutos colhidos estavam bem maduros e com a cor preta, característica que é fundamental para boa aceitação pelo consumidor, esse valor está de acordo aqueles citados por Boer e Ayub (2011) para a mesma cultivar. Esses valores indicam que os frutos estão maduros, caracterizando frutos escuros e pouco brilhantes (SOUZA, 2007).

O número de hastes deixadas durante a poda afeta a produtividade da amora-preta cv. Tupy.

Para os parâmetros produção por planta e número de frutos por planta o número de hastes ideal foi 7,8 . Considerando facilidade de manejo e produtividade recomenda-se trabalhar com 6 hastes por planta.

O número de hastes por planta não interferiu na massa fresca, sólidos solúveis, firmeza e coloração dos frutos. 


\section{Referências}

ANTUNES, L. E. C. Aspectos fenológicos, propagação e conservação pós-colheita de frutas de amoreira preta (Rubus spp) no sul de Minas Gerais. 1999. Tese (Doutorado em Fitotecnia) - Universidade Federal de Lavras, Lavras.

Aspectos técnicos da cultura da amora-preta. Editado por Luis Eduardo Corrêa Antunes, Maria do Carmo Bassols Raseira. Pelotas: Embrapa Clima Temperado, 2004.

ANTUNES, L. E. C.; DUARTE FILHO, J.; SOUZA, C. M. Conservação pós-colheita de frutos de amoreirapreta. Pesquisa Agropecuária Brasileira, Brasília, v. 38, n. 3, p. 413-419, 2003.

ANTUNES, L. E. C.; REgINA, M. A.; DUARTE FILHO, J. A cultura da amora-preta. Belo Horizonte: Epamig, 2002. 28 p. (EPAMIG. Boletim técnico, 69).

BOER, A.; AYUB, R. A. Armazenamento em atmosfera modificada e refrigerada de amora-preta cv. Tupy em diferentes estádios fenológicos. In: ENFRUTE, 12., 2011, Fraiburgo, SC. Anais... Fraiburgo: [s. n], 2011. v. II. p. 13.

BROETTO, D.; BOTELHO, R. V.; PAVANELLO, A. P.; SANTOS, R. P. Cultivo orgânico de amora-preta cv. Xavante em Guarapuava-PR. Revista Brasileira de Agroecologia, Bahia, v. 4, n. 2, p. 2208-2212, 2009.

CRANDALL, P. C.; DAULENY, H. A. Raspberry management. In: GALLETTO, G. J.; HIMELRICK, D. G. (Ed.). Small fruit crop management. Englewood Cliff, N.J.: Prentice Hall, 1990. p. 157-213.

EMPRESA BRASILEIRA DE PESQUISA AGROPECUÁRIA - EMBRAPA. Centro Nacional de Pesquisa de Solos. Sistema de produção da amoreirapreta. Brasília: Embrapa, 2008.
FACHINELLO, J. C.; HOFFMANN, A.; SANTOS, A. M. dos. Amoreira-preta, framboesa e mirtilo: pequenos frutos para o sul do Brasil. In: CONGRESSO BRASILEIRO DE FRUTICULTURA, 13., 1994, Salvador. Resumos... Salvador: Sociedade Brasileira de Fruticultura, 1994. v. 3, p. 989-990.

PAGOT, E.; SCHNEIDER, E. P.; NACHTIGAL, J. C.; CAMARGO, D. A. Cultivo da amora-preta. Bento Gonçalves: Embrapa, 2007. (Circular técnico, n. 75).

SANTOS, A. M. dos; RASEIRA, M. do C. B. Lançamento de cultivares de amora-preta. Pelotas: Embrapa/CNPFT. 1988. (EMBRAPA. Informativo, 23).

SANTOS, A. M.; RASEIRA, M. C. B.; MADAIL, J. C. M. Amora-preta. 2. ed. Brasília: Embrapa, 1997. 61 p. (Coleção Plantar, 33).

SILVA, G. J. F.; CONSTANT, P. B. L.; FIGUEIREDO, R. W.; MOURA, S. M. Formulação e estabilidade de corantes de antocianinas extraídas das cascas de jabuticaba (Myrciaria ssp.). Alimentos e Nutrição, Araraquara, v. 21, n. 3, p. 429-436, 2010.

SOUSA, M. B. Amora - qualidade pós colheita. [S. 1]: PO AGRO DE\&D, 2007. p. 28 p. (Divulgação AGRO 556. n. 7)

STRIK, B. C.; CLARK, J. R.; FINN, C. E.; BAÑADOS, M. P. Worldwide blackberry production. Hortechnology, Alexandria, v. 17, n. 2, p. 205-213, 2007.

TAKEDA, F. Winter pruning affects yield components of "Black Satin" Eastern Thornless blackberry. HortScience, Alexandria, v. 37, n. 1, p. 101-103, 2002.

TORRES, L. M. Características fisicas e químicas da amora-preta armazenada sob refrigeração. 2007. Trabalho de Conclusão de Curso (Graduação em Agronomia) - Universidade Estadual Paulista, Ilha Solteira. 